\title{
The Application of GIS in The Digital Oilfield Construction
}

\author{
Xu Xiaohong ${ }^{1}$,Shao Yanlin ${ }^{1}$ \\ ${ }^{1}$ School of Geosciences, Yangtze University, \\ JingZhou China 434023 \\ E-mail:xuxh6523@sina.com
}

\author{
Fu Jilin ${ }^{2}$,Sun Zhihua ${ }^{2}$,Xu Xin ${ }^{3}$ \\ ${ }^{2}$ CNPC Niger Petroleum S.A. Niamey Niger \\ ${ }^{3}$ Iowa Wesleyan College, The United States of \\ America
}

\begin{abstract}
In the 21 century, the construction of oil and gas resources information system has stepped into the mature and development stage, However, it also faces two technical difficulties: multi-data integration and the integration of attribute information and location information. This paper analyzes the technical features and advantages of Geographic Information System (GIS) and lists the application methods of GIS in the construction the oil and gas resources information system. It proposes the classification scheme of oil and gas resources information. By applying GIS spatial database technology, basic oil and gas resources information, including graph and data, can be managed collectively at one database platform. Based on GIS technology, it can provide the diversified information query method between space orientation and attribute data. By using the multi-data integration technology supported by GIS, it realizes the flexible transformation and transfer of spatial data. Based on GIS vector drawing ability, it realizes the flexible geological maps thematic mapping technology. With the help of GIS spatial analysis, it realizes oil and gas decision support functions such as virtual drilling, et al.. And it can be applied to the construction of oil and gas resources information system.
\end{abstract}

Keywords-Resources Information System; Geographic Information System; Spatial Database; Multi-source Data

\section{INTRODUCTION}

From the end of the last century, digital oilfield construction has been carried out in major oil fields around the world. In 2001, the construction of the digital oil field was on the National Key Technology Research and Development Program of China during the "10th Five-Year Plan" list; In the end of 2003, the digital oilfield research of the Shengli oilfield was listed as a 863 national plan of scientific and technological research, and the Shengli oilfield has explicitly put forward the strategic objective of realizing the digital oilfield at the primary stage; in 2004, Daqing Oilfield proposed that technologies need to be transformed from large-scale computing centers to a distributed network information center, and It also raised the "digital oilfield" strategy. Digital oilfield has demonstrated a wide range of potential applications. Digital oilfield construction can dramatically improve the exploration and development of oilfields and decision support levels, and it can promote the sustainable development of oilfields; the construction of the digital oilfield can also optimize the production process, and it can significantly improve the quality of oilfield production operation; digital oilfield construction can promote the further oilfield reform, therefore , the level of oilfield management could be improved ${ }^{[1]}$. However, the theory and technology system of the digital oilfield is not fully mature, it needs to be explored and practiced continuously, and it demands more consummation.

In October 2009, China Digital Oilfield Ten Years Forum Summit Defines the digital oilfield from both the broad and narrow perspective. Generalized digital oilfield holds that the digital oilfield is an advanced stage of information technology applied in oilfield, and that it is a high integration of oilfield management with computer network, data and application system. Digital oilfield consists of digital oil services, digital corporate cultures and digital staff and so on. Wang Quan, from the Daqing oilfield, raised the seven-layers digital oil model ,and it is one of the major representatives of generalized digital oilfield ${ }^{[2]}$. the narrow definition originated from the concept of "digital globe",which was put forward by the former US vice president Gore at the OGC conference in 1998. Digital oilfield is part of the digital globe, Professor Liu Xuefeng held that digital oilfield is a GIS-based information platform about oilfield enterprise information infrastructure and management layer, and that it is a oil field online spatial information service system built on the framework of digital globe ${ }^{[3-6]}$. He Shenghou ,et al. made a similar explanation about digital oilfield in 2002 [4]. Either form the broad or the narrow perspective,GIS ,which blend property information with space orientation information system,is sure to be the core technology in digital oil field construction and implementation. By applying the spatial information organization and the management capacity of GIS, it can assembles the seismic, logging and geological pictures and data involved in the resources exploration and collectively stores them at one database platform;it can provide the flexible information query geological mapping functions.With the help of GIS spatial analysis, it can realizes the oil and gas assistant decision-making abilities. It has been applied to CNPCNP companies in South Africa, Niger overseas project that in the provision of petroleum industry geographical information system service.

\section{GIS APPLICATION}

With the development of GIS, it has been applied in 
various industries till now.The primary application of GIS in the oil and gas exploration information system are shown as follows: ${ }^{[5-6]}$.

1) Thematic mapping: the powerful mapping capabilities that can accomplish almost all of the maps in oilfield production process (such as comprehensive histogram of geologic, tectonic map, isopach map, various of geological profiles, sedimentary facies, reservoir distribution, evaluation and source rock distribution, evaluation and forecast of oil and gas resources, and so on);

2) Data management and sharing: by employing GIS, it can effectively manage various basic maps and data at one platform and establish an interactive correlation between spacial information and property data, which enables the highly efficient data management, and based on based on spatial database and network services it can also offer efficient data sharing .

3) Decision support and analysis: based on the strong spatial analysis function of GIS, it can build a professional analysis algorithms and process flow, providing decision-support functions for oil and gas exploration; and the application of GIS technology in "digital oilfield" is bound to set up a new milestone in the information construction of oilfields.

\section{Classify OIL AND GAS FUndAMENTAL INFORMATION}

As to the basic information involved in resources exploration (including basic data, geological maps, and so on), according to the basic steps and objectives of reservoir description, they can be divided into three categories: shaft, profile, block distribution ${ }^{[6-7]}$.

1) Shaft: It means one-dimensional data and maps associated with the shaft, such as: logging data, explanation, hierarchical data, analysis data of single well facies, logging data and production data, et al., these information can be born on a single well bar chart;

2) Profile: It means sectional drawings associated with cross section and the data relied on these sectional drawings, such as: seismic profiles, stratigraphic correlation profiles, reservoir profiles, flooded sections, sedimentary facies profiles, et al.;

3) Block distribution: It means the data and maps which relied on a certain range within a block, they are mainly born on plans., such as well location map, construction plans, sedimentary facies plans,reservoir physical properties distribution plans,interlayers distribution plans,flooded plans, oil-bearing maps, et al.

Almost all of the information involved in the the work of oil and gas exploration, and organization model based on spatial information can be born by geologic maps.In order to help systems organize, manage and expression the information involved in the exploration and development, with references to the "Petroleum Industry Guidelines for Information Classification and Coding" (SY/T 578,521,999), map elements and result data were encoded (Table 1) and input into the system database according to certain encoding rules.

\begin{tabular}{|l|l|l|l|}
\hline $\begin{array}{l}\text { Geologi } \\
\text { cal code }\end{array}$ & $\begin{array}{c}\text { Drawing } \\
\text { element }\end{array}$ & $\begin{array}{l}\text { Geologi } \\
\text { cal code }\end{array}$ & $\begin{array}{c}\text { Drawing } \\
\text { element }\end{array}$ \\
\hline 2 & Lithology & 43 & Logging \\
21 & Sedimentary & 44 & information \\
212 & rock & 4401 & Interpretation \\
213 & Conglomerate & 4402 & Oil layer \\
21301 & Sandstone & 4404 & Bad oil layer \\
21305 & Conglomerati & 44011 & Oil-water \\
22 & c sand & 5 & layer \\
23 & Fine & 51 & Water layer \\
31 & sandstone & 52 & Well symbol \\
32 & Magmatite & 53 & Prospecting \\
& Metamorphite & & well \\
& Contact & & Well \\
& relationship & & Development \\
& Regional & & well \\
& structure & & \\
\hline
\end{tabular}

Table 1 encoding for map elements classification

\section{APPLICATION}

A. Oil and gas resources information system data management

The maps and data involved in the oil and gas exploration are organized in the spacial information models, and based on the spatial database engine, they can be managed collectively in the large-scale commercial relationship databases (SQL Server, Oracle, DB2, et al.), with the help of its relationship , it can achieve efficient data security control and data sharing. At the same time,in order to complete the property data management, the platform provides two means : the management of corresponding property information through space objects: or the employment of data management tools provided by the system(Figure 1 ).

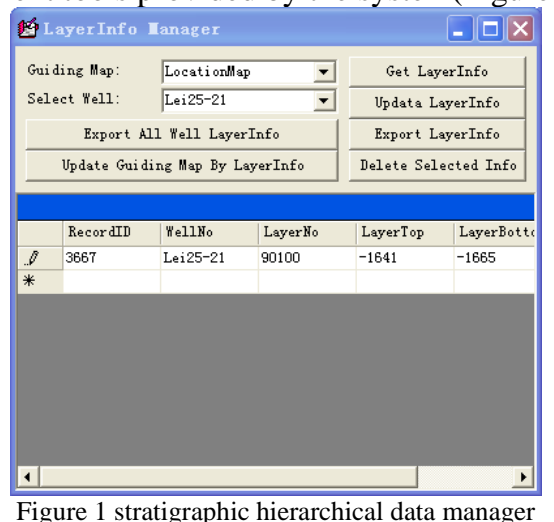

\section{$B$. Oil and gas resource information query}

Flexible space query function based on GIS, exploration development foundation information platform provides three important query method: basic information inquiries from the diagram to the property; space relationship query from diagram to diagram and the SQL query from property conditions to the corresponding primitive, Figure 2 illustrates the query from primitive 
(drilling) to its corresponding basic attribute and graphic document (drilling composite histogram).

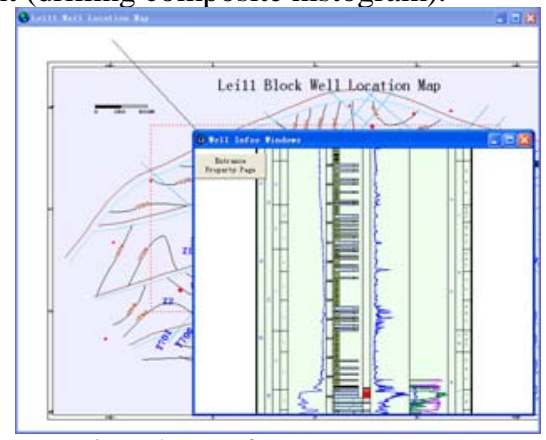

Figure 2 query from property to map

C. Oil and gas resources multi-source information int egration

The basic data and results information involved in the oil gas exploration research have various formats. For example, seismic interpretation Is usually processed by professional softwares like LandMark, And the outcomes are output by it, thus they will follow fixed formats.Geologic maps might be made by Discover, CoreDraw, Surfer, AutoCAD and other mapping softwares. In order to transfer all the basic data and achievements discussed above to the spatial database for unified management, there are two methods as follows: if the format of graphic documents and data are compatible with GIS platform, they can be moved to spatial database directly by multi-source data integration technology; otherwise they should be moved to spatial database by self-developed components. As to seismic interpretation, this system contains import components, which is compatible with LandMark achievement data volume.

\section{Geological Thematic mapping}

At the present, the major forms of the oil and gas exploration maps are either paper maps or electronic maps which are incompatible with GIS platform, by employing the traditional way of map delineation in the system, there will be two problems: it is difficult to guarantee its accuracy and it would be too much time-consuming and labor-intensive. In view of the characteristic and requests of geological maps, the system, which is based on the secondary development of GIS platform, achieves the fast automatic to semi-automatic mapping method of geological maps, it also realizes the management of geological maps, vector drawing and map editing (Figure 3). In order to meet the demands of the information technology efficiency required by the oilfields and corporations, the platform also provides the auto to semi-automatic thematic mapping function of conventional maps, such as drilling comprehensive histogram, even well sections, and planer distribution maps.(Figure 4).
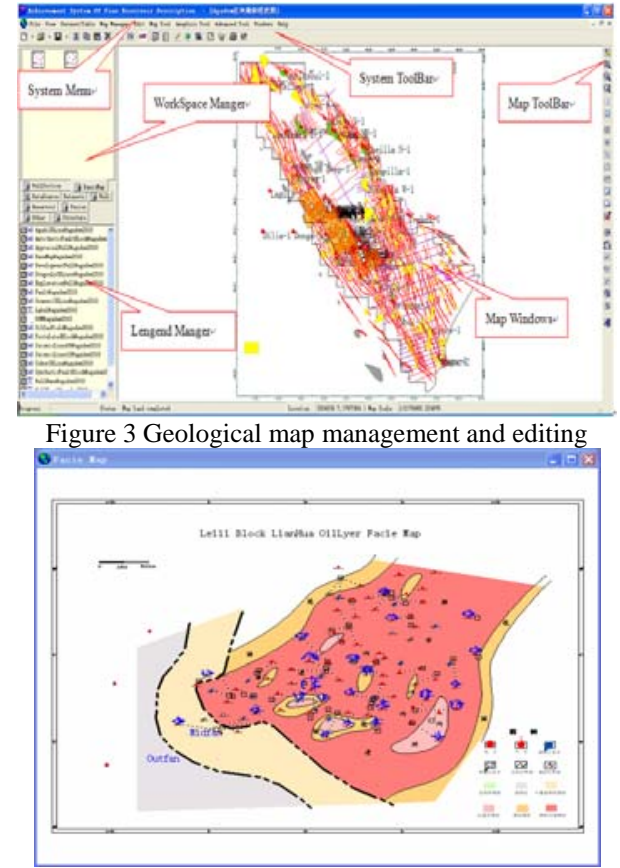

Figure 4 Geological thematic mapping

E. Oil and gas exploration and decision support

Decision support is the highest level of GIS application in oil and gas exploration, the basic information platform of exploration and development is based on DEM technology, it constructs the three-dimensional model of underground geologic bodies. Based on this model, the platform has achieved two functions: the generation of virtual drilling and sections in any directions, it also provides the reference for the decision support of oil and gas exploration and development, Figure 5 shows the generation of virtual drilling, by selecting the location of virtual drilling anywhere in the work area, the platform can generate the stratigraphies reached by the virtual drilling and its geological hierarchical data, and it can automatically draw up the well drilling histogram.

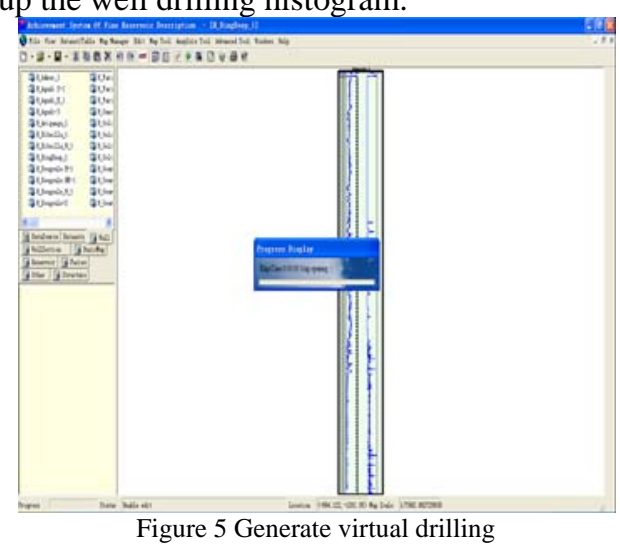

\section{CONCLUSION}

Through the application of GIS technology in oil and gas exploration, the following achievements are made in 
this paper.

1) By using the GIS-based spatial data management technology, unified management of geological graphic document and basic data is realized. It promotes the The level of oil and gas exploration data management, which make the document sharing and security control more convenient.

2) Based on GIS, a flexible inquiry of exploration information is obtained.

3) By applying the GIS Multi-source data integration technology and self-developed data import components, the warehousing of existing research results and data is realized.

4) Due to the auto to semi-auto thematic mapping technology of geological maps, the progress of oil-gas exploration informationization is accelerated.

5) The GIS spatial analysis offers the oil and gas decision support, which makes an exploratory study for the further application of GIS in oil and gas exploration.

\section{REFERENCE}

[1] Duan Hongjie, Digital Oil Field from Theory to Practice. Di gital Petroleum \& Chemical, 2004, 4, 11-13. (in Chinese)

[2] Wang Quan, Yag bin, Zhang Wanli. Digital Oilfield and its Basic Framework, Oil-Gasfield Surface Engineering,2004,23(12),47 -48.(in Chinese)

[3] L.R. Records, D. Shimbo, Petroleum Enterprise Intelligence i n the Digital Oil Field [A], SPE127355, 2010.

[4] He Shenghou, Wei Zhongya,The Theory and Practice on Dig ital Oil Field, Geography and Territorial Research,2002,18(2),5-7. (i n Chinese)

[5] Liu Xuefeng,Meng Lingkui,Gong Wenping etc.Application of Geographic Information System (GIS) to the Exploration and Dev elopment of Oil and Gas, Geospatial Information 2003,1(2),12-16. (in Chinese)

[6] Liu Xuefeng, He Zhen-ming,He Youbin. The Oil and Gas E xploration Aid Decision-making Based on GIS: Principles, Methods and Applications [M].Petroleum Industry Press, 2008. (in Chinese) [7] D. Holland, Managing the journey to the digital oil field, T he Leading Edge, 2004, 23, pp.1137-1138. 